\title{
The Principles and Practice of Psychiatric Rehabilitation
}

\author{
Srinivasan Tirupati \\ Hunter New England Mental Health Service; The University of Newcastle, Australia
}

\begin{abstract}
People with severe mental disorders experience difficulty in functioning in several domains of life that are all not related to the illness and the symptoms. Medical management for severe mental disorders leads to improvement in symptoms and distress that may not always correlate with functional improvement. A comprehensive rehabilitative care is necessary to reengage the person in life activities and full participation in mainstream life. The Rehabilitation interventions are to be person centered with supports from the environment and removal of barriers to progress recovery. Rehabilitative care should be enhanced by integrated recovery-orientated practices that sustain hope, promote self-agency. This paper discusses the definition of psychiatric rehabilitation and a model of the processes involved.

Key Words

Psychiatric Rehabilitation-Recovery-Mental illness- Mental Health Services
\end{abstract}

\section{INTRODUCTION}

Progress in development and use of pharmacological agents and other treatments including electroconvulsive therapy made it possible for many people with severe mental illness like schizophrenia live outside the restrictive and costly long-stay hospital environment. People with severe mental illness have the same life goals as everyone else. These goals include a safe, decent, affordable and permanent place to live, access to education and employment, friendships and community participation in leisure and growth activities. In other words, they want to live satisfying, functional, meaningful lives, not just be stable. ${ }^{1}$ However people are discharged form highly structured and supervised environment of hospital care into community with nothing more than a prescription for medicines. ${ }^{2}$ Reduction in symptoms of the schizophrenia was not seen to correlate with functional improvement. ${ }^{3}$ The focus of the clinical-medical model of care on amelioration of symptoms and risk did not address the functional impairment of these individuals across multiple domains like cognition, living skills, social skills, education and work skills.

Correspondence: Dr.Srinivasan Tirupati

Psychiatric Rehabilitation Services,

20 Stewart Avenue

Hamilton NSW 2303, Australia

Email: Srinivasan.Tirupati@hnehealth.nsw.gov.au
Psychiatric Rehabilitation (PR) or Psychosocial Rehabilitation (PSR) is of crucial importance in addressing the issue of facilitating a person with severe mental illness to progress beyond clinical improvement to full functional capacity and participation in life. The discipline promotes the adoption of a broad, holistic approach to care for the mentally ill and challenges the mental health services to think more inclusively of people with severe mental illness with focus on inherent strengths and possibilities of recovery. ${ }^{4,5}$

Many see PR as essential part in the management of all severe and enduring mental disorders and that every mental health service providing care should provide to its clients but not everyone fully understands its purpose and processes. Though PSR is a specialized program addressing needs of certain clientele, requiring special skills and infrastructure to practice, some argue that rehabilitation is 'everybody's job' and does not involve any special skills on part of the clinician or the status of the client receiving it. Perhaps reluctance to accept the discipline of psychiatric rehabilitation stems from the fact it is easy to define but any explanation belies the complexities of the process. ${ }^{4}$

This paper aims to discuss the position of PR and issues related to its scope and principles of practice in mental health care. The discussion is relevant to all mental disorders but with a focus on severe mental disorders like schizophrenia.

\section{Defining Psychiatric Rehabilitation:}

For sake of discussion I have selected here two meanings of the term rehabilitation to bring forth some interesting aspects of how one understood and, thereby, defined rehabilitation. They are taken from 
two on-line dictionary sources. These two definitions are not popular or cited in literature on PR. I selected them only for the purpose of setting a starting point to discuss three important aspects of rehabilitation- what it means, the process involved, and its objectives.

Definition one was by the Free Dictionary ${ }^{6}$ which reads "Rehabilitation is a treatment or treatments designed to facilitate the process of recovery from injury, illness, or disease to as normal a condition as possible". Definition two by Medicinenet ${ }^{7}$ defines rehabilitation as "The process of helping a person who has suffered an illness or injury restore lost skills and so regain maximum self-sufficiency".

With reference to what rehabilitation means, the first definition addresses it as 'a treatment or treatments' and the second one calls it a 'process of helping'. English Oxford Dictionary ${ }^{8}$ defines treatment as "Medical care given to a patient for illness or injury". The term treatment/s would imply it as a medical model of care with focus on management of illness. The term 'process of helping' does not identify the process as one of 'medical' in nature. The nature of help can be of any nature or from any source including medical care.

Coming to the issue of process of rehabilitation, the term 'treatment' in the definition one can be seen as a directive one-way process of 'medical care given' by the provider to the receiver, (patient/ client) with the receiver having a secondary or no role in the process. The term 'helping' used in the definition two by Medicinenet, is defined as 'making it easier or possible for someone to do something by offering them one's services or resources. ${ }^{8}$ It does not identify any hierarchy in relationship between a provider and receiver but only on a 'process'. In helping, a support is 'offered' rather than 'given' (unlike in 'treatment'). Process of helping also involves the recipient as an active participant seeking, receiving and working with the help received.

With regard to objectives of rehabilitation, one definition looks at a "[return] to as normal condition as possible" while the other looks at "regain maximum self-sufficiency". The 'normal condition' predicates a standard status of living that everyone else around the affected persons have and affected people are able or have to achieve that or as much of it as they can. The standard set is external to the person, to a 'norm' prevalent in the environment where the person lives, a 'norm' probably defined by that environment. The Medicinet's ${ }^{7}$ definition of "regaining maximum self-sufficiency" implies no external 'norm' but something that is directly relevant to only the individual. It describes performance tasks of living with a personal sense of sufficiency rather than an external benchmark. The role of the person in determining the outcome is more explicit in the second definition than the first. This in turn would bring the focus on the person as the centre of the process of rehabilitation, as the driving force behind what he or she wants to attain and to what extent.

Against the background of this discussion we can look at definitions of psychiatric rehabilitation in PR literature. The definitions in literature differ according to whether they focus on goals, method, philosophy or linkages to the broader field of rehabilitation. ${ }^{9}$ Rutman ${ }^{10}$ defined it as the systematic utilisation of a combination of specific modalities to assist in the community rehabilitation of persons with psychiatric disabilities. Bachrach ${ }^{11}$ defines it as a therapeutic approach that encourages a mentally ill person to develop his or her fullest capacities through learning and environmental supports. The definition by Psychosocial Rehabilitation/ Réadaptation Psychosociale Canada PSR/RSP Canada ${ }^{12}$ is more comprehensive and reads

“... promotes personal recovery, successful community integration and satisfactory quality of life for persons who have a mental illness or mental health concern. Psychosocial rehabilitation services and supports are collaborative, person directed, and individualized, and an essential element of the human services spectrum. They focus on helping individuals develop skills and access resources needed to increase their capacity to be successful and satisfied in the living, working, learning and social environments of their choice and include a wide continuum of services and supports."

The definition underscores several aspects of PSR- goals that are more related to living than merely being healthy. The definition includes a life lived within the natural environment, and outcomes in emotional terms of satisfaction. The person is seen playing the central role in rehabilitation and the services are centred on the person's needs and choices rather than the other way round, i.e., person depending on what services provide. The foremost tenet of PR is its base on strengths model rather than deficits model. It works with a person's strengths for individualized goal setting and recovery different from the traditional, illnessbased medical approaches which focus on problems and deficits of the person. The availability and access to a wide continuum of supports and services is deemed necessary for the individual to progress in his or her recovery from the impact of illness and the environment.

\section{Process of rehabilitation:}

From the definition of PR it is understood that it is a complex intervention that occurs along a continuum of care and involves a variety of goals, processes, providers and settings. It can be understood using the concepts used in the International Classification of Functioning, Disability and Health (ICF) $(2001)^{13}$ which is a revision of the International Classification of Impairment, Disability and Handicaps (ICIDH), first published by the World Health Organization in 1980. The ICF is a useful tool to comprehend the conse- 
quences of mental illness in all its dimensions, including impairments at the structural or functional level of the body, at the person level with respect to activity limitations, and at the societal level with respect to restrictions of participation. These three dimensions replaced the negative descriptions in the ICIDH- impairments, disabilities and handicaps respectively. Further ICF includes the dimension of environmental factors as part of the classification. This is in recognition of the importance of the role of environmental factors in preventing/overcoming impairments, facilitating functioning and participation in life activities. The positive or negative impact of the environmental factors depends on whether they act as facilitators or a barriers.

Table 1: Components of Rehabilitative care

\begin{tabular}{|c|c|c|}
\hline Phase & Scope & Providers * \\
\hline Remediation & $\begin{array}{l}\text { - Treat manifestations of the } \\
\text { - Mental illness } \\
\text { - Manage physical health issues } \\
\text { - Understand treatment process, } \\
\text { prognosis } \\
\text { - Developing adjusting to diag- } \\
\text { nosis } \\
\text { - Manage Legal and financial } \\
\text { issues } \\
\text { - Relapse management, manage- } \\
\text { ment of triggers, vulnerabilities } \\
\text { - Manage impact of family } \\
\text { - Building Trust and hope that is } \\
\text { real and sustainable } \\
\text { - Family education and support }\end{array}$ & $\begin{array}{l}\text { Early Intervention pro- } \\
\text { grams, } \\
\text { Emergency Mental Health } \\
\text { care services } \\
\text { Acute/non-acute clinical } \\
\text { care services } \\
\text { Acute care hospitalization } \\
\text { Medications } \\
\text { Community Mental Health } \\
\text { Services } \\
\text { Clinical Rehabilitation } \\
\text { services- community and } \\
\text { hospital based } \\
\text { Non clinical services in- } \\
\text { cluding NGOs }\end{array}$ \\
\hline Restoration & $\begin{array}{l}\text { - Developing/Rebuilding coping } \\
\text { skills } \\
\text { - Restore psychological and func- } \\
\text { tional competencies } \\
\text { - Strengthen cognitive abilities } \\
\text { - Social skills, daily living skills } \\
\text { - Support to education and em- } \\
\text { ployment } \\
\text { - Work thorough grief and loss } \\
\text { due to illness } \\
\text { - Develop a sense of self and } \\
\text { goal-directedness } \\
\text { - Promote self-agency } \\
\text { - Family education and support }\end{array}$ & $\begin{array}{l}\text { Clinical Rehabilitation } \\
\text { services- community and } \\
\text { hospital based } \\
\text { Non clinical services in- } \\
\text { cluding NGOs } \\
\text { Psychological and Occupa- } \\
\text { tional therapy support } \\
\text { Housing support } \\
\text { Primary health care ser- } \\
\text { vices } \\
\text { Acute/non-acute clinical } \\
\text { care services }\end{array}$ \\
\hline Reconnection & $\begin{array}{l}\text { - Develop a balance of independ- } \\
\text { ence and social inclusion } \\
\text { - Utilization and strengthening } \\
\text { and refinement of skills gained } \\
\text { in Restoration phase } \\
\text { - Proving opportunities, reducing } \\
\text { barriers } \\
\text { - Establish and strengthen social, } \\
\text { community connections } \\
\text { - Gradual adjustment of support } \\
\text { towards promoting self-reliance } \\
\text { - Empowerment of person and } \\
\text { family and social support sys- } \\
\text { tems }\end{array}$ & $\begin{array}{l}\text { Non clinical services in- } \\
\text { cluding NGOs } \\
\text { State Health and Welfare } \\
\text { and } \\
\text { Disability Support systems } \\
\text { Community support } \\
\text { Peer support groups } \\
\text { Family support groups } \\
\text { Advocacy } \\
\text { Primary health care ser- } \\
\text { vices } \\
\text { Clinical Rehabilitation } \\
\text { services- community and } \\
\text { hospital based } \\
\text { Acute/non-acute clinical } \\
\text { care services }\end{array}$ \\
\hline
\end{tabular}

Using the ICF framework, Psychiatric Rehabilitation can be viewed as working at four interrelated domains- at the impairment level, functioning and activity and in participation and environment. The Integrated recovery-oriented Model (IRM) of mental health care describes this model in detail. ${ }^{4}$ The IMR describes the components of Remediation, Restoration and Reconnection relating to impairment, activity and participation dimensions respectively. This ' $3-\mathrm{R}$ ' model is shown in figure 1. Each level encompasses a theoretical foundation on which a rehabilitative goals and intervention can be formulated. The nature of an intervention is defined by the goal addressed by the intervention. ${ }^{14}$ Interventions can be classified as rehabilitative when they are mainly directed towards a functional improvement of the affected individual.

Fig 1. The 3-R model of mental health care and rehabilitation (Based on Frost et al, 2017)

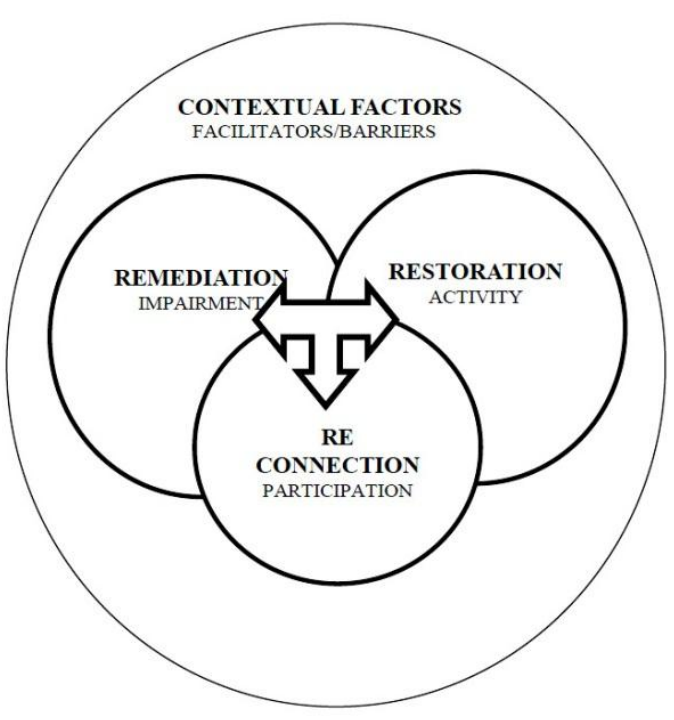

In this ' $3-\mathrm{R}$ 'model, Remediation describes reduction in the psychological, physical and social consequences of the illness as the individual passes through the acute phase of the illness; Restoration is about enabling and gaining/regaining competencies of the person that occurs in tandem and with Remediation; Reconnection is about reconnecting and establishing a place for the person in the community and exploring opportunities for independence and social inclusion with a renewed sense of hope and confidence. These three processes are overlapping and dynamically influence each other. For example remediation of symptoms would facilitate better restoration of function and that feeds back into a better mental and physical health status. In the same way a person well integrated into society has better opportunities, motivation and supports towards better functioning and improved health state.

\section{When rehabilitation?}

This differentiation of PR from other components of mental health care brings in a dilemma over where its application sits in the overall process of helping persons recover. It is not uncommon practice when a person is deemed "to be fit/ready for rehabilitation 
now" implying that there is a stage in course of illhealth where a person needs rehabilitation and does not at other stages. A person is often identified as ready for rehabilitation when the acute clinical symptoms have subsided to an extent that makes practice of rehabilitation possible. This attitude is possibly driven by the understanding that rehabilitation work is about getting a person back on his feet and getting on with life in terms of performing activities of his/her life in the society and thereby integrate with it and this can happen only when the clinical symptoms or risk status is well under control with medications/treatment. It is not often viewed that rehabilitation is about the person and not the illness and that the person needs a rehabilitative approach at all stages of the illness. Rehabilitation process has a life span approach with its relevance and application through all phases of ill health. The content and process of rehabilitation may vary depending on clinical status of the individual but it is rarely irrelevant at any time to the person.

The 3-R model is about mental health services as a whole that is aimed at promoting a comprehensive recovery of the individual. The process of rehabilitation is applicable at all stages of recovery process. The nature and intensity of the rehabilitative input varies with the stage of recovery of the person. The phases of recovery are shown in Figure 2 and the components of rehabilitation at each phase are described in table 1. The table shows the scope of care provided at each phase of rehabilitation and the sources that are engaged in the process. Acute and non-acute mental health care services including short, intermediate and long-term hospitalisation need to be available at all phases given the relapsing and sometimes deteriorating course of illnesses like schizophrenia and severe mood disorders. In a recovery oriented rehabilitation program the need for and utilisation of these service are aimed to be minimised with progressively greater and intensive role for non-clinical services, family and community support and welfare support services. In a similar vein, the need for non-medical supports that work towards goals like providing support to the persons and their social network to come to grips with the illness, instilling hope, restoration of confidence and skills to re-enter mainstream life should start from the day one they come in contact with services. These support processes will need to take on a much bigger role as the acute phase of the illness abates. Availability of a comprehensive and effective rehabilitation program across the continuum of care can be cost-effective over acute and purely medically oriented mental health care by shortening hospital admissions, improving activities and participation of people in life activities and thus leading to improved quality of life.

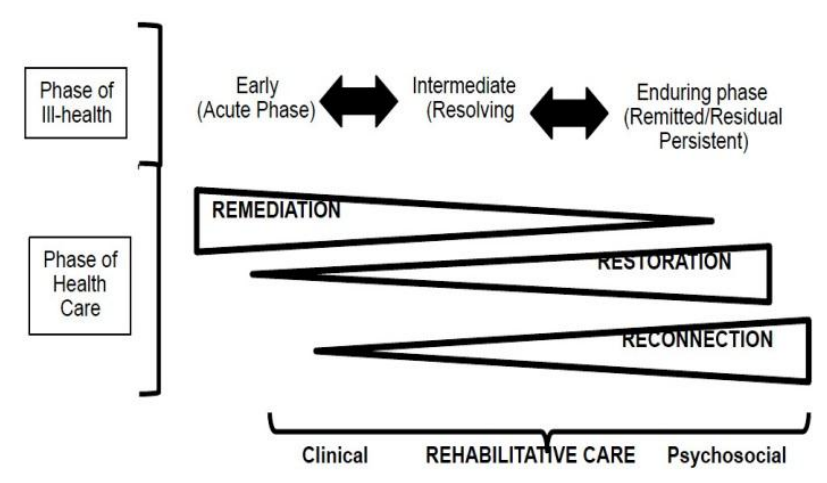

Fig.2: Rehabilitation and Phase of Recovery

(Based on Frost et al, 2017)

\section{Rehabilitation and Recovery:}

The broader concept of "recovery" as a general philosophy and model was first popularized in regard to recovery from substance abuse/drug addiction. Application of recovery models to psychiatric disorders is comparatively recent with main impetus coming from within the consumer/survivor/ex-patient movement, a grassroots self-help and advocacy initiative from the United States of America during the $1980 \mathrm{~s}$ and $90 \mathrm{~s}^{15}$ There are several definitions of recovery in mental health. The oft-cited definition of recovery by Anthony ${ }^{16}$ is that it is a deeply personal, unique process of changing one's attitudes, values, feelings, goals, skills and/or roles, a way of living a satisfying, hopeful, and contributing life even with limitations caused by the illness involving development of new meaning and purpose in one's life as one grows beyond the catastrophic effects of mental illness. Substance Abuse and Mental Health Services administration ${ }^{17}$ defines recovery as a process of change through which individuals improve their health and wellness, live a self-directed life, and strive to reach their full potential. The American Psychiatric Association ${ }^{18}$ in its position statement on recovery noted that the concept emphasizes a person's capacity to have hope and lead a meaningful life with focus on wellness and resilience and encourages persons to participate actively in their care and increasing their ability to successfully cope with life's challenges.

It can be seen that the descriptions of PR overlap with that of Recovery raising a doubt if these two are same, different or overlapping. They can be viewed as two sides of the same coin. They both view the person as the centre of action. Rehabilitation is a process that has in its sights certain specific needs of persons with mental illness and works towards fulfilling them. On the other hand, Recovery can be understood as a philosophy of practice that forms the foundation for the whole process of rehabilitation to occur. The definitions of rehabilitation incorporate the philosophy of recovery in them. This can make definition of rehabilitation and recovery look similar. Rehabilitation process involves only some aspects of a person's journey from impairment to functionality and participation but the recovery model of approach to 
care is overarching across the entire spectrum of the person's journey from illness to health, including and beyond the rehabilitative processes. For example, an active rehabilitative goal or process may not be practical in a person in acute clinically severe phase of the illness when management of immediate risk and safety concerns may be paramount but a recovery-oriented care applies even under such situations. A recovery oriented psychiatric rehabilitative care is about people having opportunities for choices and living a meaningful, satisfying and purposeful life. It empowers individuals to make their own choices and take responsibility of their lives, building on their strengths. It predicates the creation of the appropriate environmental support systems to promote the individual's progress in their recovery.

\section{CONCLUSION}

The progression from the restrictive, exclusionary medical model of care to a space where the persons with mental illness were given a central role in their recovery was made possible by adoption of an open and inclusive rehabilitative model of care that aimed at recovery of the person as a whole. Characteristics of a successful PSR program include long-term interventions delivered close to patient's natural environments that often combine skills training for the individuals along with environmental support. ${ }^{19}$ Understanding the principles of rehabilitative model of care is required for its proper and effective practice, development of necessary services and supports required for its practice and enhanced global outcomes for people with severe mental disorders.

\section{REFERENCES}

1.Drake RE, Whitley R. Recovery and severe mental illness: description and analysis. Can J Psychiatry 2014; 59: 236-42.

2. Anthony WA, Farkas M. Primer on the psychiatric rehabilitation process. Boston: Boston Univeristy, Centre for Psychiatric Rehabilitation; 2009.

3. Meltzer HY. Cognitive factors in schizophrenia: cases, impact, and treatment. CNS Spectrum 2004; 9: 15-24.

4. Frost BG, Tirupati S, Johnston S, Turrell M, Lewin TJ, Sly KA, Conrad AM (2017) An Integrated Recovery-oriented Model (IRM) for mental health services: evolution and challenges. BMC Psychiatry. 2017; 17:22 DOI 10.1186/s12888-016-1164-3
5. World Health Organisation. World Report on Disability. Geneva: World Health Organisation; 2011.

6. Corrigan PW, Mueser KT, Bond GR, Drake RE, and Solomon P, editors. Principles and practice of psychiatric rehabilitation. An empirical approach. New York:Guilford Press; 2008.

7. Rutman, ID. Introduction. In: Spaniol L, Brown MA, Blankertz L, Burnham DJ, Dincin J, Furlong-Norman K, et al, editors. An introduction to psychiatric rehabilitation. Boston: International Association of Psychosocial Rehabilitation Services; 1994:4-8.

8. Bachrach LL. Psychosocial rehabilitation and psychiatry in the care of long-term patients. Am J Psychiatry 1992; 149:1455-1463.

9. Free Dictionary. [Internet] Available from https://medicaldictionary.thefreedictionary.com/rehabilitation

10. Medicinenet. Medical Definition of Rehabilitation [Internet] Available from:

https://www.medicinenet.com/script/main/art.asp?articlekey=5288)

11. English Oxford Living Dictionaries [Internet]. Available from: https://en.oxforddictionaries.com/definition/help

12. British Columbia Psychosocial rehabilitation. Advanced practice. What is psychosocial rehabilitation? [Internet]. 2018. Available from: https://www.psyrehab.ca/pages/what-is-psr.

13. World Health Organization. International Classification of Functioning, Disability and Health (ICF) Geneva: World Health Organization; 2001

14. Rossler W. Psychiatric rehabilitation today: an overview. World Psychiatry 2006; 5: 151-157.

15. International Mental Health Collaborating Network History of Recovery movement [Internet]. 2018. Available from: https://imhcn.org/bibliography/history-of-mental-health/history-ofrecovery-movement/

16. Anthony WA. Recovery from mental illness: the guiding vision of the mental health service system in the 1990s. Psychosoc Rehab J 1993; 16: 11-23.

17. Substance Abuse and Mental Health Services administration (SAMHSA) [Homepage on the internet] Available from:

https://store.samhsa.gov/shin/content/PEP12-RECDEF/PEP12RECDEF.pdf

18. American Psychiatric Association. Position Statement on Use of the Concept of Recovery [Internet]. 2005 Jul. Available from:https://www.psychiatry.org/file\%20library/aboutapa/organization-documents-policies/policies/position-2005recovery-concept.pdf

19. Mueser KT, Drake RE, Bond GR. Recent Advances in Psychiatric Rehabilitation for Patients with Severe Mental Illness. Harv Rev Psychiatry 1997; 5: 123-37. 